\title{
Percepções sobre a Covid-19 e seus impactos ambientais por meio de uma sequência didática
}

\author{
Perceptions about Covid-19 and its environmental impacts through a didactic sequence \\ Percepciones sobre Covid-19 y sus impactos ambientales a través de una secuencia didáctica
}

Recebido: 01/05/2021 | revisado: 03/05/2021 | aceito: 04/05/2021 | publicado: 17/05/2021

\author{
Antonio Carlos Nogueira Sobrinho \\ ORCID: https://orcid.org/0000-0002-9921-3350 \\ Faculdade de Educação, Ciências e Letras de Iguatu, Brasil \\ Universidade Estadual do Ceará, Brasil \\ E-mail: caiosobrinho@yahoo.com.br \\ Soraya Marques Ribeiro \\ ORCID: https://orcid.org/0000-0002-1606-7731 \\ Secretaria de Educação do Estado do Ceará, Brasil \\ E-mail: soraya_marques21@hotmail.com \\ Môngolla Keyla Freitas de Abreu \\ ORCID: https://orcid.org/0000-0002-2656-6868 \\ Secretaria de Educação do Estado do Ceará, Brasil \\ E-mail: mongolla.abreu@gmail.com
}

\begin{abstract}
Resumo
A pandemia da Covid-19 como uma crise sanitária e humanitária tem alertado a sociedade para suas consequências a curto e longo prazo. Diante disso, o presente estudo apresenta e discute os dados obtidos a partir da aplicação de uma sequência didática a respeito da Covid-19 e seus impactos ambientais. Esta pesquisa é de natureza descritiva, abordagem qualitativa e interpretativa com análise a partir do discurso do sujeito coletivo. Desenvolvida com estudantes da disciplina de Princípios de Etnobiologia e Educação Ambiental de um curso de licenciatura em Ciências Biológicas, esta sequência consistiu em duas nuvens de palavras, seguidas de rodas de conversa para a discussão crítico-reflexiva, um questionário e por fim, a elaboração de desenhos sobre as percepções a respeito deste percurso pedagógico. As nuvens de palavras e as rodas de discussão trouxeram temas atrelados à saúde mental, como medo e ansiedade, além de termos alinhados a questão ambiental, como lixo e poluição. A maioria dos estudantes apontou a questão socioemocional como um dos maiores impactos da pandemia, inclusive sendo citada como a dimensão da sustentabilidade que mais foi impactada no contexto atual. Logo, o sujeito como parte integrante do ambiente, pode através do reconhecimento do cuidado e dos impactos ambientais, avançar em práticas educativas ambientais que promovam o desenvolvimento cada vez mais sustentável.
\end{abstract}

Palavras-chave: Meio ambiente; Pandemia; Sustentabilidade; Saúde coletiva.

\begin{abstract}
The Covid-19 pandemic as a health and humanitarian crisis has alerted society to its short- and long-term consequences. Therefore, the present study presents and discusses the data obtained from the application of a didactic sequence regarding Covid-19 and its environmental impacts. This study is of a descriptive nature, with a qualitative and interpretative approach with analysis based on the discourse of the collective subject. Developed with students from the discipline of Principles of Ethnobiology and Environmental Education of a degree course in Biological Sciences, this sequence consisted of two word-clouds, followed by conversation circles for critical-reflective discussion, a questionnaire and finally, the elaboration drawings on the perceptions regarding this pedagogical path. The word-clouds and discussion circles brought topics linked to mental health, such as fear and anxiety, in addition to having aligned the environmental issue, such as garbage and pollution. Most students pointed to the socio-emotional issue as one of the biggest impacts of the pandemic, including being cited as the dimension of sustainability that was most impacted in the current context. Therefore, the subject as an integral part of the environment, can, through the recognition of care and environmental impacts, advance in environmental educational practices that promote increasingly sustainable development.
\end{abstract}

Keywords: Environment; Pandemic; Sustainability; Collective health.

\section{Resumen}

La pandemia de Covid-19 como crisis sanitaria y humanitaria ha alertado a la sociedad sobre sus consecuencias a corto y largo plazo. Por ello, el presente estudio presenta y discute los datos obtenidos de la aplicación de una secuencia didáctica sobre Covid-19 y sus impactos ambientales. Este estudio es de carácter descriptivo, con enfoque 
cualitativo e interpretativo con análisis basado en el discurso del sujeto colectivo. Desarrollada con estudiantes de la disciplina de Principios de Etnobiología y Educación Ambiental de la carrera de Licenciatura en Ciencias Biológicas, esta secuencia constó de dos nubes de palabras, seguidas de círculos de conversación para la discusión críticoreflexiva, un cuestionario y finalmente, los dibujos de elaboración sobre las percepciones respecto a este camino pedagógico. Las nubes de palabras y los círculos de discusión trajeron temas vinculados a la salud mental, como el miedo y la ansiedad, además de haber alineado el tema ambiental, como la basura y la contaminación. La mayoría de los estudiantes señalaron el tema socioemocional como uno de los mayores impactos de la pandemia, incluido el hecho de ser citado como la dimensión de sostenibilidad que se vio más afectada en el contexto actual. Por tanto, el sujeto como parte integral del medio ambiente, puede, a través del reconocimiento de los cuidados y los impactos ambientales, avanzar en prácticas educativas ambientales que promuevan un desarrollo cada vez más sustentable.

Palabras clave: Medio Ambiente; Pandemia; Sustentabilidad; Salud colectiva.

\section{Introdução}

No contexto atual, a pandemia da Covid-19 tem desafiado o mundo a sobreviver a uma crise sanitária e humanitária. A doença é causada pelo novo coronavírus (SARS-CoV-2) e teve início na China no final de 2019. A Covid -19 foi declarada como uma pandemia pela Organização Mundial de Saúde (OMS), em março de 2020, chamando a atenção para seu caráter emergencial na saúde pública global (Who, 2020; Huang et al., 2020). Este cenário tem desencadeado uma série de impactos socioambientais, que preocupam as gerações atuais e futuras.

A sociedade está vivendo, neste momento de pandemia, uma crise que alcança dimensões políticas, econômicas, sociais e sanitárias (Saviani, 2020). Contudo, é preciso destacar alguns impactos ambientais que persistem neste momento de crise, tais como, a exploração desordenada de recursos naturais, a produção de resíduos e sua destinação inadequada. Além disso, é preciso olhar para as desigualdades sociais, bem como para a condição socioemocional da população, frente a um longo período de isolamento social e ao elevado número de mortes decorrentes da Covid-19.

A partir do escopo da crise ambiental, é necessário utilizar práticas educativas ambientais como forma de mitigar impactos e promover ações sociais mais sustentáveis, pois se "a educação sozinha não transforma a sociedade, sem ela tampouco a sociedade muda" (Freire, 2000, p. 67). De acordo com Sauvé (2016), é fundamental uma Educação Ambiental voltada para o relacionamento saudável e de respeito entre o ser humano e o meio ambiente, em que a humanidade possa aprender a conviver entre seus pares e com outras formas de vida presentes no ambiente.

A Educação Ambiental é um processo contínuo, em que o ser humano ao passo que se conscientiza do seu meio, adquire conhecimentos, valores, habilidades, experiências e determinação para agir, individual e coletivamente, a fim de resolver problemas ambientais, presentes e futuros (Reigota, 2017). Assim, as práticas educativas ambientais devem ir para além de um conteúdo científico curricular e interdisciplinar, buscando aproximar os conteúdos do cotidiano dos alunos, viabilizando a aprendizagem significativa e a mudança conceitual de forma positiva nesta construção socioambiental. Vale destacar que para a aprendizagem significativa ocorrer, deve-se levar em consideração o conhecimento prévio do aluno (Moreira, 2015).

Além disso, é necessário que as práticas educativas ambientais venham acompanhadas de alternativas metodológicas que proporcionem a aprendizagem de forma participativa. Nesse contexto, a sequência didática surge como uma ferramenta motivadora do processo de ensino e aprendizagem, estimulando os estudantes a trazerem seus conhecimentos prévios e perceberem a necessidade da aquisição de novos saberes (Castellar \& Machado, 2016).

A Educação Ambiental precisa estar presente de forma constante na formação de professores, especialmente de professores de Ciências e/ou Biologia. A Educação Ambiental na perspectiva crítica e emancipadora poderá contribuir significativamente com a formação de agentes transformadores da sociedade, promovendo a construção de uma sociedade cada vez mais sustentável. Portanto, os cursos de licenciatura são locais privilegiados para a formação de educadores ambientais, haja vista que os futuros docentes poderão contribuir com a consciência ambiental dos estudantes (Gutiérrez \& Prado, 2013). 
Diante do desafio de pesquisar e conhecer sobre a Covid 19 e seus impactos ambientais, este trabalho apresenta uma sequência didática implementada com estudantes universitários do curso de Licenciatura em Ciências Biológicas. Tal trabalho mostra a relevância de pensarmos esta temática a partir da ressignificação de conceitos e ideias previamente elaborados, valorizando os conhecimentos dos alunos e suas realidades.

\section{Metodologia}

A partir da questão norteadora da pesquisa, que deveria elencar os impactos ambientais causados pela pandemia da Covid-19, foi estruturado este estudo, que é de natureza descritiva, com abordagem metodológica qualitativa e interpretativa. Para a condução deste trabalho foi utilizado o discurso do sujeito coletivo, que assente em agrupar os discursos individuais por semelhança ou complementaridade, de modo a elaborar categorias temáticas amplas sobre o fenômeno analisado (Minayo, Assis, Souza, 2005; Lefèvre \& Lefèvre, 2000). Além de apresentar um relato de experiência sobre o uso de uma sequência didática aplicado com os alunos do curso de Licenciatura em Ciências Biológicas.

A pesquisa foi conduzida em sala de aula, seguindo a dinâmica e o planejamento pedagógico da disciplina de Princípios de Etnobiologia e Educação Ambiental, sendo as atividades articuladas pelos docentes-investigadores com auxílio da monitora da disciplina. Os sujeitos da pesquisa foram 29 alunos cursantes da disciplina, que foi ofertada exclusivamente por via remota, em virtude da pandemia da Covid-19.

A estruturação da sequência didática foi conduzida à luz dos critérios previamente discutidos por Méheut (2005), a saber: epistemológico, relacionado aos conteúdos e situações problema; psicocognitivo, em consonância com os aspectos cognitivos e a compreensão dos termos, ideias e conteúdos abordados; didática, referente aos aspectos do currículo e planejamento da disciplina, como carga-horária, cronograma e ementa.

A sequência didática foi proposta e implementada na disciplina de Princípios de Etnobiologia e Educação Ambiental, disciplina obrigatória no currículo do curso de Licenciatura em Ciências Biológicas da Faculdade de Educação, Ciências e Letras de Iguatu da Universidade Estadual do Ceará (UECE). Esta disciplina tem como objetivo analisar o gênero humano como potencial transformador da natureza e compreender a utilização de recursos naturais nas soluções ambientais e sociais, bem como organizar os aspectos ambientais na questão legal, logística e educacional, além de abordar aspectos de etnobiologia e suas concepções em uma visão histórica, social, antropológica e biológica.

Em virtude do isolamento social e das medidas de distanciamento impostas pelo governo estadual em decorrência da pandemia da Covid-19, as aulas na UECE foram ministradas excepcionalmente por via remota, com o auxílio de plataformas digitais, como o Google Meet, utilizado para os encontros síncronos. Os alunos foram assessorados pela monitora da disciplina, aluna integrante do Programa de Monitoria Acadêmica da universidade. A sequência didática foi planejada para implementação no ensino remoto, utilizando sites e aplicativos interativos. Foram propostas ações que se completavam em dois encontros distintos, de modo que a sequência teve início em uma aula e encerrou no encontro da semana seguinte, como organizado na Figura 1. 
Figura 1. Organização da sequência didática, implementada na disciplina universitária.

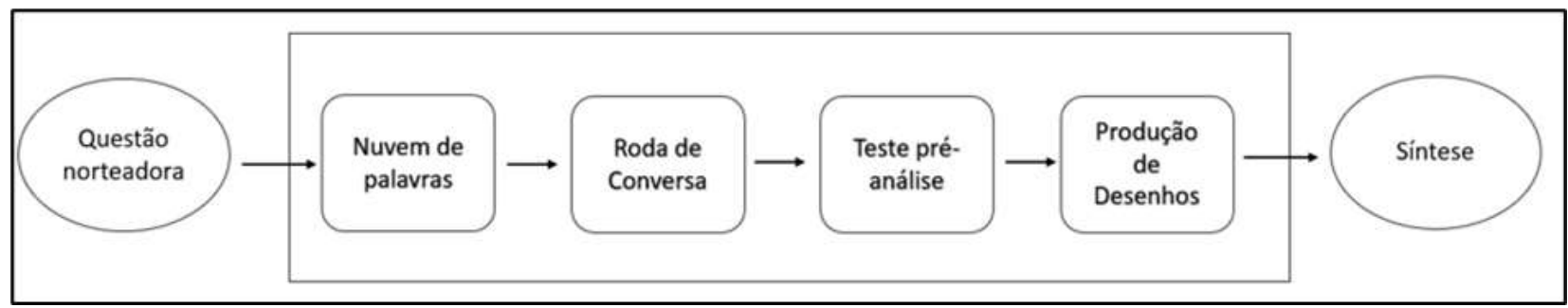

Fonte: Autores.

O processo de avaliação desse estudo se une ao processo próprio de avaliação da aula, sendo utilizados instrumentos avaliativos inseridos nas etapas da sequência didática, como as narrativas dos alunos, o uso de um formulário com questões opinativas e a produção de desenhos, utilizados para o fechamento e síntese das atividades. A coleta de dados ocorreu fazendo uso da observação e gravação da aula, com posterior transcrição na íntegra das falas dos alunos, sendo elaborado um protocolo de observação participante, baseado em modelo proposto por Moreira e Caleffe (2008), além de outros dois instrumentos, o questionário e os desenhos. O questionário abordou perguntas opinativas sobre impactos ambientais, medidas de mitigação de impactos ambientais, impactos na saúde e sustentabilidade. Os desenhos foram utilizados para síntese da aula, em que os alunos deveriam promover uma conclusão da aula com suas impressões particulares da temática abordada.

\section{Resultados e Discussão}

Após o momento de acolhida dos alunos, foi disponibilizado um link da plataforma digital Mentimeter® (https://www.mentimeter.com/app) com a pergunta "Que palavras-chave representam para você as consequências da Covid19?" com três espaços para respostas dos alunos. De modo simultâneo, à medida que os alunos respondiam com as palavraschave, a plataforma gerava uma nuvem de palavras (Figura 2) com as respostas dos alunos organizadas por número de repetições, para esta atividade foi organizado o tempo de cinco minutos para preenchimento.

Dos 39 alunos matriculados na disciplina, 29 compareceram ao primeiro encontro e construíram coletivamente a nuvem de palavras, cujos termos mais citados foram ansiedade, medo, perdas, empatia, morte, sofrimento e desemprego. A sequência didática teve como ponto de partida uma questão problematizada, ou seja, um problema autêntico que não tem uma resposta direta e objetiva. Deste modo, os alunos precisam estabelecer conexões com conhecimentos prévios, com distintos pontos de vista, experimentando as habilidades de organização de ideias e argumentação, conforme salienta Puig (2010).

Em seguida foi iniciada uma roda de conversa sobre as palavras-chave presentes na nuvem, em que os alunos foram convidados a participar por meio do chat, ou ainda de áudio, com falas e debate de ideias, sendo planejado um tempo de quinze minutos para essa atividade.

Um dos alunos relatou o cansaço por estar frequentemente em frente às telas, pois devido ao isolamento social, todas as atividades estão ocorrendo de forma remota. Considerando as mudanças ocorridas na dinâmica da sala de aula em um curto espaço de tempo, é natural que os alunos se sintam desanimados devido a necessidade de adaptação ao novo formato de ensino. Brooks et al. (2020) afirma que um dos fatores estressantes é decorrente da duração prolongada da pandemia, gerando medos, frustrações e diminuição do rendimento. 
Figura 2. Nuvem de palavras construída a partir da pergunta norteadora: Que palavras-chave representam para você as consequências da Covid-19?

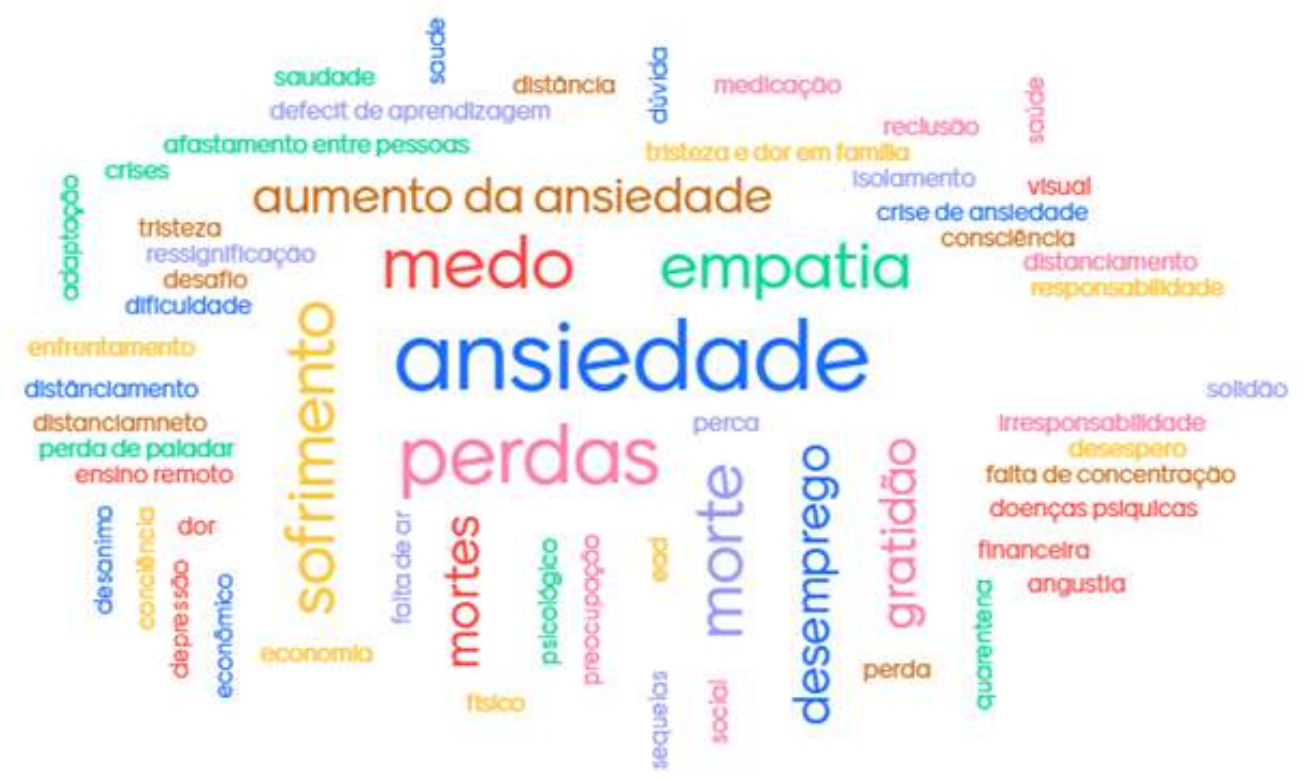

Fonte: Autores.

Outros alunos também falaram sobre a aflição de estar constantemente dentro de casa, o que ocasionou diversos problemas de ordem psicológica, como o agravamento e/ou surgimento da ansiedade devido ao medo de contrair a doença, elevado número de mortes, sentimento de insegurança, dentre outros fatores. Diversos autores têm relatado o aumento da incidência da ansiedade, medos, síndrome do pânico, depressão, além de implicações na ordem afetiva e social devido a este tempo pandêmico (Maia \& Dias, 2020; Enumo \& Linhares, 2020). Em uma pesquisa realizada com estudantes universitários da China, foi observado que 53,8\% dos estudantes apresentaram impactos psicológicos moderados e/ou severos de ansiedade, depressão e estresse durante a pandemia (Wang et al., 2020). Segundo Holmes et al. (2020), essas alterações bruscas na rotina e no modo de vida da população geram impactos de ordem física, ou seja, na fisiologia do corpo, mas principalmente alterações cognitivas, fazendo com que as preocupações relativas à saúde mental estejam no topo das discussões.

Na nuvem também surgiram palavras de caráter positivo, como empatia, gratidão, revelando que alguns alunos conseguiram ressignificar as dificuldades enfrentadas durante a pandemia da Covid-19, transformando em algo positivo. Segundo Rashid e Seligman (2018), o foco nos aspectos positivos diminui o sofrimento e melhora a qualidade de vida, fornecendo um novo olhar diante dos desafios, tornando-se mais resiliente, otimista e compassivo.

Após o relato em torno das consequências referentes à pandemia da Covid-19, o discurso começou a ser direcionado para a temática ambiental, contextualizando com notícias jornalísticas contemporâneas, como o porquê da redução no ritmo econômico não diminuir os indicadores de mudanças climáticas (Portal G1, 2021a) e como a vida marinha respondeu à redução sem precedentes do tráfego de navios (Portal G1, 2021b). Na sequência, os alunos foram orientados a abrir novamente um link da plataforma digital Mentimeter ${ }^{\circledR}$ com mais uma pergunta norteadora. Foi questionado aos alunos "Quais os principais impactos ambientais da Covid-19?”, sendo solicitado o preenchimento com até 4 palavras ou frases curtas, gerando deste modo a segunda nuvem de palavras (Figura 3). Os principais termos em ordem de repetição nesta nuvem foram poluição, lixo hospitalar, resíduos, lixo e desmatamento. 
Figura 3. Nuvem de palavras construída a partir da pergunta norteadora: Quais os principais impactos ambientais da Covid$19 ?$

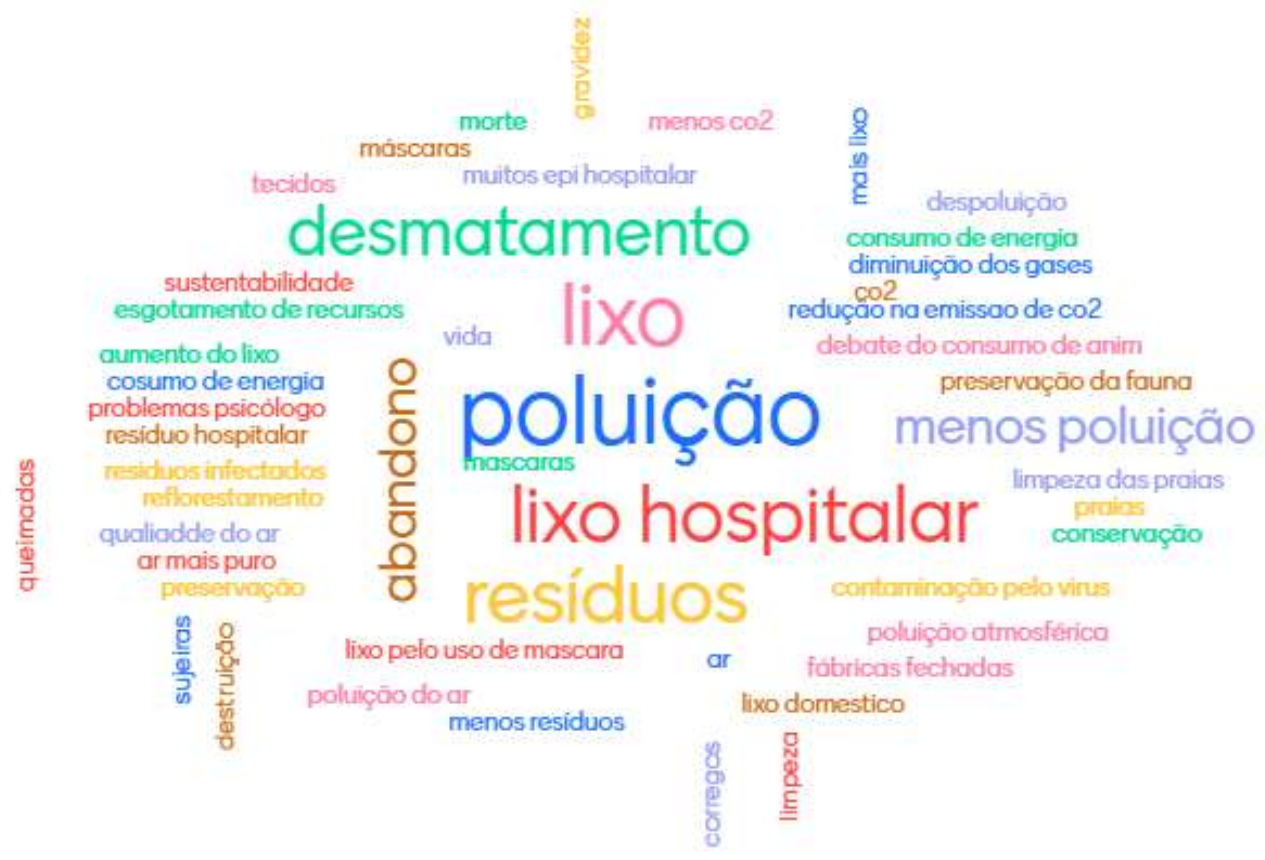

Fonte: Autores.

A partir das palavras-chave e frases mencionadas pelos alunos foi iniciada uma roda de conversa, em que foi estabelecido um elo lógico entre as palavras/frases citadas e seus imperativos em relação ao meio ambiente e a Covid-19. A palavra poluição foi a mais citada, sendo abordada de distintos modos pelos alunos. Alguns alunos relataram a poluição como indicador de intensificação do impacto ambiental, afirmando que devido a pandemia houve um aumento do consumo de fastfood, do uso de máscaras descartáveis que ocasionou uma alta na produção de resíduos domésticos e hospitalares. Segundo Peng et al. (2020) um aumento no consumo de produtos de higiene, bem como de equipamentos de proteção individual elevou de 10 a 20 vezes a produção de lixo hospitalar.

Um aluno ressaltou a diminuição da poluição devido ao isolamento social em decorrência da desaceleração econômica, o que gerou uma diminuição na liberação de gases de efeito estufa, sendo nesse caso um efeito positivo para o meio ambiente. A pandemia revelou os impactos da atividade antrópica, uma vez que a diminuição da circulação de pessoas melhorou a qualidade do ar e da água (Braga et al., 2020).

Esta segunda roda de conversa teve uma duração aproximada de vinte e cinco minutos e contou com a participação da monitora, organizando as falas dos alunos via chat e registrando as posições dos alunos, para posterior síntese deste momento de vivência. Na sequência, os alunos responderam a um questionário com 5 questões, sendo duas objetivas e três subjetivas, versando sobre as impressões e pontos de vista sobre a relação entre a pandemia da Covid-19 e o meio ambiente. Os alunos responderam online, com o auxílio da plataforma digital Google Formulário®, sendo disponibilizado um tempo de quinze minutos para o preenchimento do questionário.

No encontro seguinte, houve a acolhida com um vídeo que trazia imagens e cenários do meio ambiente sadio e em desequilíbrio, tendo como música de fundo, a composição Absurdo, de Vanessa da Mata, que dialoga com o impacto do homem no meio ambiente e as consequências a médio e longo prazo. A letra da composição foi disponibilizada para os alunos, sendo estimulada uma discussão após a exibição do vídeo. Para essa atividade foi disponibilizado um tempo de quinze minutos. Como síntese da sequência didática, foi solicitado dos alunos o fechamento da aula com a produção de um desenho, 
que deveria mostrar as impressões deles sobre os momentos vividos durante a sequência didática, sendo o desenho uma atividade assíncrona, devendo ser posteriormente postada na sala de aula virtual. Por fim, foi planejado um tempo para os alunos se manifestarem livremente sobre a aula, as experiências vividas e as aquisições com os assuntos discutidos ao longo da sequência, incluindo os desenhos produzidos.

\subsection{As narrativas construídas e analisadas sob a ótica do questionário opinativo}

Na primeira questão foi indagado aos alunos se havia relação entre a pandemia e o meio ambiente, todos os alunos afirmaram que existe relação. Na questão seguinte foi questionado quais seriam essas relações existentes entre a Covid-19 e o meio ambiente. A maioria das respostas dos alunos estavam associadas ao aumento da poluição ocasionado pela produção de lixo provenientes do ambiente doméstico e hospitalar (Figura 4). Também foram encontradas respostas que mostravam o efeito positivo da pandemia sobre o meio ambiente associada à redução da poluição por causa da melhoria da qualidade do ar e da água devido a diminuição das atividades econômicas impostas pelo isolamento social, e consequente redução da circulação de pessoas nas cidades. Também houve respostas que associavam o surgimento da pandemia ao desequilíbrio ambiental ocasionado pelo homem.

Figura 4. Percepção dos alunos sobre a relação existente entre a pandemia e a COVID-19.

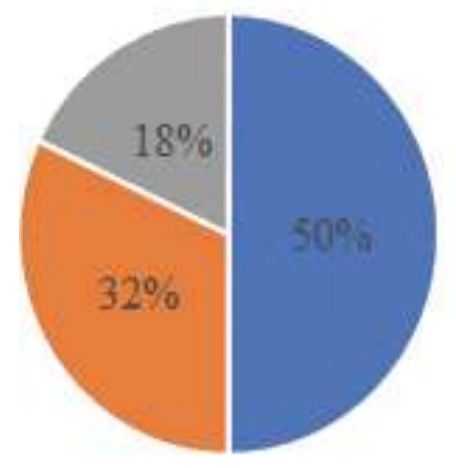

\section{- Melhoria da qualidade do ar e da água}

\section{- Produção de residuos}

\section{- Surgimento da pandemia relacionado ao desequilibrio ambiental}

Fonte: Autores.

$\mathrm{Na}$ questão seguinte foi perguntado aos alunos quais seriam as possíveis estratégias para mitigar os impactos ambientais ocasionados pela Covid-19, tendo sido abordado por eles diversas temáticas relacionadas à Educação Ambiental (Tabela 1).

Por meio das respostas dos alunos observa-se que eles contemplaram como medidas para diminuir os impactos ambientais, as bases do tripé da sustentabilidade que estão ligados a aspectos econômicos, ambientais e sociais, nos mostrando que o aluno compreende que a educação ambiental é uma área das ciências ambientais ampla, que busca formar indivíduos para a conservação e prevenção dos recursos naturais, abordando seus aspectos econômicos, políticos, sociais, ético, ambiental, dentre outros (Pereira, Silva, Carbonari, 2011). 
Tabela 1. Estratégias propostas pelos alunos para diminuir os impactos ambientais causados pela Covid-19.

\begin{tabular}{c|c}
\hline Categoria & Quantidade de sujeitos \\
\hline Ação conjunta das secretarias do meio ambiente & 2 \\
Reaproveitamento de materiais & 4 \\
Responsabilidade social atrelada a conscientização & 12 \\
Descarte correto do lixo & 8 \\
\hline Medidas de prevenção & 2 \\
\hline Auxílio financeiro & 1 \\
\hline
\end{tabular}

Fonte: Autores.

A responsabilidade social associada à conscientização ambiental foi a medida mais citada pelos alunos para diminuir os impactos da Covid-19 no ambiente. Diante deste contexto pandêmico é natural que a responsabilidade social seja uma das formas de mitigação mais citadas, pois mais do que nunca foi perceptível a necessidade da visão coletiva acima da individual. Já que cada cidadão necessitou se privar do convívio social e adotar medidas sanitárias adequadas para prevenir e reduzir a transmissibilidade do vírus.

Desse modo, a responsabilidade social caracteriza-se por um conjunto de atitudes baseadas em valores éticos e morais que visam diminuir os impactos negativos ocasionados ao ambiente no qual estamos inseridos. Portanto, é essencial a conscientização e participação dos sujeitos nos processos de transformação do meio ambiente, realizando atos de cuidado e preservação que irão melhorar a qualidade de vida de todos os seres vivos (Marques, 2020).

O descarte correto do lixo também foi uma das opções mais citadas pelos alunos, pois na pandemia houve um aumento significativo na produção de lixo doméstico e hospitalar. Nas residências ocorreu um aumento no consumo de produtos de higiene e o descarte de diversos materiais que antes eram reutilizados, mas que agora devido a pandemia precisam ser descartados para evitar o contágio com o vírus. Nos ambientes hospitalares também houve uma alta na produção de resíduos devido a utilização de equipamentos de proteção individual descartáveis, além de insumos necessários para a esterilização dos ambientes hospitalares.

Independente dos resíduos produzidos pela população, estes precisam ser descartados de forma correta, pois o manejo inadequado pode causar contaminações no solo, no ar e inclusive aumentar o risco de contágio por diversas doenças (Silva, 2020). Portanto, é necessário que a população e as autoridades sanitárias realizem o descarte correto do lixo, com vistas a diminuir os impactos à saúde e ao meio ambiente.

O sujeito por diversas vezes tem dificuldade em reconhecer o cenário no qual está inserido, contudo, é preciso instigálo a perceber o meio e os impactos decorrentes das ações antrópicas, a fim de encontrar o caminho para a construção de uma sociedade sustentável. Atualmente, a ecopedagogia é uma proposta de teoria em construção, e objetiva educar para pensar globalmente, educar os sentimentos, ensinar a identidade terrena, formar para a consciência planetária, formar para a compreensão, e educar para a simplicidade e para a quietude (Gadotti, 2011).

Diante disso, os estudantes foram indagados sobre suas percepções a respeito da presença de algum impacto ambiental nas proximidades de sua residência. Assim, 70\% informaram que identificam impactos desta natureza nas proximidades das suas residências, e todos citaram os impactos por eles reconhecidos.

O impacto citado em destaque foi a produção e destinação inadequada do lixo, sendo citado lixo hospitalar, tais como máscaras e luvas, acúmulo de lixo nas ruas, devido à redução na coleta de lixo pela gestão pública municipal, e acúmulo de 
lixo em local inadequado, causando alagamentos no período chuvoso. Ainda nesta perspectiva, citaram sobre o comprometimento da vegetação, devido ao acúmulo de lixo em locais inadequados. A produção e acúmulo inadequado de lixo é algo que preocupa a humanidade há muito tempo, sendo alvo de discussões. Contudo, a sociedade capitalista precisa entender a origem do problema para que a partir disso possa pensar em como mitigar tais impactos ambientais. Arrais, Carvalho e Teo (2016) citam que a exploração excessiva dos recursos naturais a fim de produzir bens de consumo, gera uma grande quantidade de lixo, aumentando a poluição dos ambientes, pois grande parte desses resíduos não são reciclados e uma parcela considerável não possuía a destinação correta.

Outro termo citado foi a poluição, especialmente do ar, da água e do solo. Curiosamente citaram o uso de queimadas e desmatamentos, especialmente como prática de preparo do solo para a agricultura, sendo a prática agrícola uma opção comum no ambiente rural diante do desemprego. Além disso, um aluno citou o alagamento vivenciado pelos moradores do município em que residem. No entanto, este alagamento é decorrente da construção em áreas indevidas e não se agravou em decorrência da pandemia, mas deve ter sido mais evidenciado devido ao fato da permanência nas residências por longos períodos do dia.

Ainda sobre a presença ou não de impactos ambientais no contexto habitacional dos estudantes, $23 \%$ dos pesquisados não identificaram impactos ambientais neste contexto, apesar de um dos estudantes dizer "Não, por incrível que pareça, fora as máscaras que vejo jogadas nas ruas, nada mais". Logo, esta frase possibilita duas interpretações: ou este estudante não reconhece as máscaras descartáveis, utilizadas na prevenção contra a Covid -19, lançadas em local indevido como impacto ambiental ou considera um impacto de pequena proporção. Vale destacar que a pandemia da Covid-19 desafiou a humanidade no manejo de resíduos de serviços de saúde de modo seguro, tanto para os trabalhadores na linha de frente dos ambientes hospitalares quanto para o ambiente doméstico (Nogueira et al., 2020).

O Desenvolvimento Sustentável requer "[...] duplo imperativo ético da solidariedade com as gerações presentes e futuras e exige a explicitação de critérios de sustentabilidade social e ambiental e de viabilidade econômica" (Sachs, p. 36, 2008). Ainda segundo o autor, este desenvolvimento consiste em oito dimensões: social, ambiental, psicológica, econômica, espacial, política nacional, política internacional e cultural; que precisam estar delineadas para que a sustentabilidade seja alcançada.

Diante disso, os estudantes foram questionados sobre qual dimensão da sustentabilidade consideram que foi mais impactada com a pandemia da Covid-19 (Figura 5).

A partir da Figura é possível perceber a dimensão psicológica com um percentual significativo diante das demais dimensões marcadas pelos estudantes. Este dado remete à necessidade da humanidade em encontrar-se com a proposta do "bem viver". O "bem viver" requer o equilíbrio entre o próprio sujeito consigo mesmo, com a sociedade, e por consequência, entre todos os seres vivos. Somente a partir da harmonização dessas três esferas será possível estabelecer uma profunda relação com a natureza da qual o ser humano faz parte (Acosta, 2015).

A segunda dimensão mais citada pelos estudantes foi a econômica, em seguida a social, e por último a ambiental. Estas estão intrinsecamente relacionadas no contexto de desenvolvimento, especialmente no momento atual de pandemia da Covid-19, que evidenciou as questões socioambientais e econômicas do mundo, especialmente do Brasil. Apesar da sociedade atual oportunizar melhor qualidade de vida, esse sistema capitalista instaurado acaba dificultando a equidade e justiça social, que se espera através da sustentabilidade (Neves \& Marques, 2017). O novo coronavírus desafiou a humanidade a se reinventar em sua essência e reformular de modo sustentável e includente a única casa comum que possui (Boff, 2020). 
Figura 5. Percepção dos estudantes sobre as dimensões do Desenvolvimento Sustentável mais impactadas com a Covid-19.

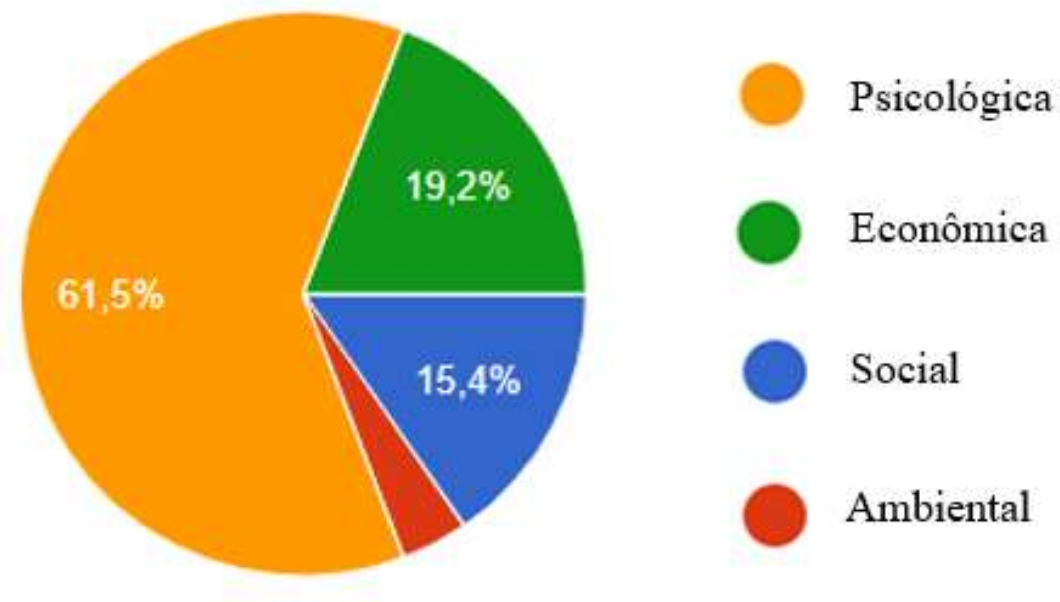

Fonte: Autores.

Os estudantes citaram de forma muito discreta o impacto ambiental ao responderem o questionamento sobre a dimensão mais afetada pela pandemia. Isso nos revela a necessidade de aumentar esforços para que as práticas educativas discorram sobre todas as dimensões envolvidas no processo, principalmente a ambiental, para que haja o desenvolvimento de uma sociedade sustentável em que o ser humano reconheça a necessidade da preservação e cuidado com o meio ambiente. Como nos diz o filósofo francês Bruno Latour, há a necessidade da humanidade modificar seu modo de vida e de exploração do planeta, pois a crise da saúde não é apenas uma crise passageira, mas trata-se de uma mudança ecológica duradoura e irreversível (Nouaillas, 2020).

\subsection{A expressão de sentimentos e a síntese dos encontros por meio de desenhos}

Os desenhos são uma forma de expressão dos sentimentos, emoções, bem como das percepções dos alunos. A ideia de solicitar o desenho dos alunos, em vez de uma resenha, ou resumo ou ainda memorial, surgiu da necessidade de apresentar uma proposta diferente para alunos no Ensino Superior. Essa quebra de paradigmas alimenta um sentimento de novo, bem como desafia os alunos a pensar em como os encontros poderiam ser sintetizados na forma de uma expressão artística.

Todos os alunos presentes nas atividades entregaram os seus desenhos, apesar das queixas de alguns quanto a falta de talento ou aptidão para desenhar, porém esse fator foi contornado pela fala do docente, deixando-os livres para se expressar independente da habilidade para a produção artística. Os desenhos foram categorizados em três eixos temáticos, a saber: crise global; impacto na saúde mental; impacto macro e microssocial.

Alguns alunos expressaram os impactos da pandemia da Covid-19 como uma crise global, não apenas na saúde pública, que é a mais afetada diretamente, bem como nos eixos ambiental, social e econômico, como pode ser observado na Figura 6, que mostra dois desenhos agrupados nesse eixo temático. Em ambos os desenhos há um globo, que certamente representa o planeta Terra, e as dimensões que representam os múltiplos olhares dos alunos para a situação pandêmica. 
Figura 6. Principais desenhos que agrupam o eixo temático, crise global.

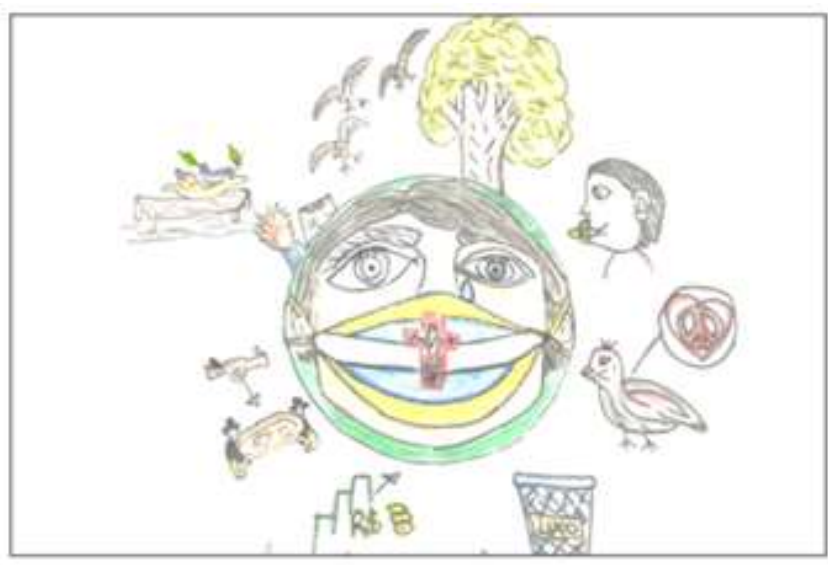

A

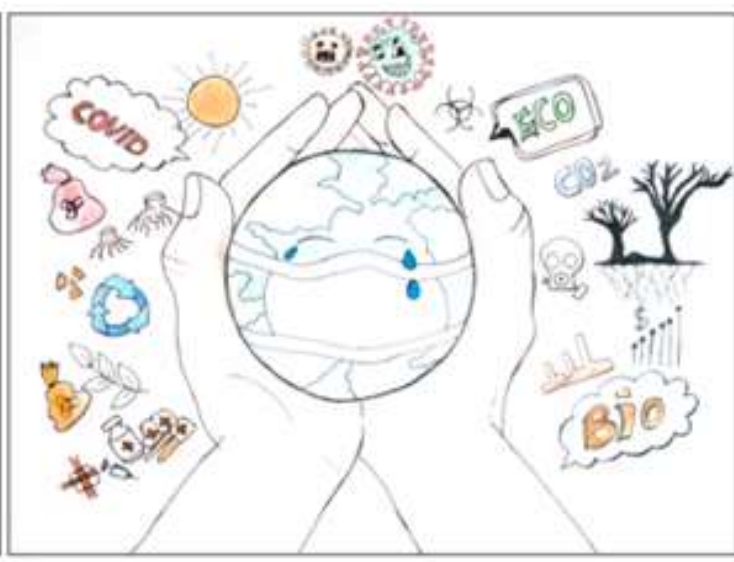

B

Fonte: Arquivo pessoal dos autores.

No desenho da Figura 6A, o aluno representou elementos da fauna e da flora. Todavia, também foram expressos elementos do capitalismo, como o lucro em alta, em contraste com as mortes, representada por dois homens segurando um caixão. Durante a roda de conversa, alguns alunos problematizaram os imperativos econômicos em detrimento do elevado número de óbitos e o iminente colapso na saúde pública. Junto com toda essa colcha de retalhos, que sumarizam os impactos da Covid-19, o aluno ainda colocou um cesto de lixo, como alerta para um problema recorrente das sociedades, que mais uma vez foi secundarizado nessa crise global. O desenho da Figura 6B, também apresenta ideia similar à do desenho anteriormente citado, contudo ele aborda apenas os elementos da ciência, como o desenvolvimento de medicamentos e imunobiológicos e a pesquisa científica com os vírus, além da dimensão ambiental, que está no escopo da disciplina e foi tema principal das discussões durante a sequência didática.

Estes desenhos apresentam o ponto de vista de dois alunos, de que a pandemia da Covid-19 apresenta múltiplos impactos, o que por nos mostra a dimensão global desses impactos. Tal como afirma Ozili e Arun (2020), essa pandemia provoca insegurança em todos os aspectos da vida, incluindo as relações sociais individuais e coletivas, os padrões de comportamento das sociedades, os hábitos e rotinas, bem como a sensação de medo e cuidado para evitar a infecção pelo vírus.

O próximo eixo temático dos desenhos produzidos pelos alunos foi o do impacto na saúde mental, organizado na Figura 7. Em uma pandemia, cujas mortes são o retrato final de uma dura e desproporcional luta contra o vírus, somando-se a isso outros problemas sociais, como a desigualdade socioeconômica, a saúde mental é um aspecto de extrema relevância, muitas vezes negligenciado por políticas públicas. Esses desenhos corroboram com os termos mais citados na primeira nuvem de palavras, que trouxe aspectos da saúde mental, como a ansiedade, o medo e as perdas, sendo desenhos reflexivos no sentido stricto, ao trazer como foco, o ser humano em momentos de reflexão.

A Figura 7A traz elementos da dimensão intrapessoal humana, ao abordar na cena, uma mulher deitada sob o chuveiro com semblante de tristeza, pensando nos efeitos do vírus não apenas no contexto médico, como também nos contextos social e das relações humanas. Em conformidade com o desenho anterior, a figura 7B representa uma criança sentada em uma carteira escolar e pensando no vírus.

Em uma pandemia, as atenções da comunidade científica, no momento inicial, são para estudar o patógeno e seus mecanismos de virulência, de modo a organizar políticas de saúde coletiva para o enfrentamento da doença, de modo que a saúde mental é secundarizada e por vezes negligenciada, segundo discutem Tucci et al. (2017). 
Figura 7. Principais desenhos que agrupam o eixo temático, impactos na saúde mental.

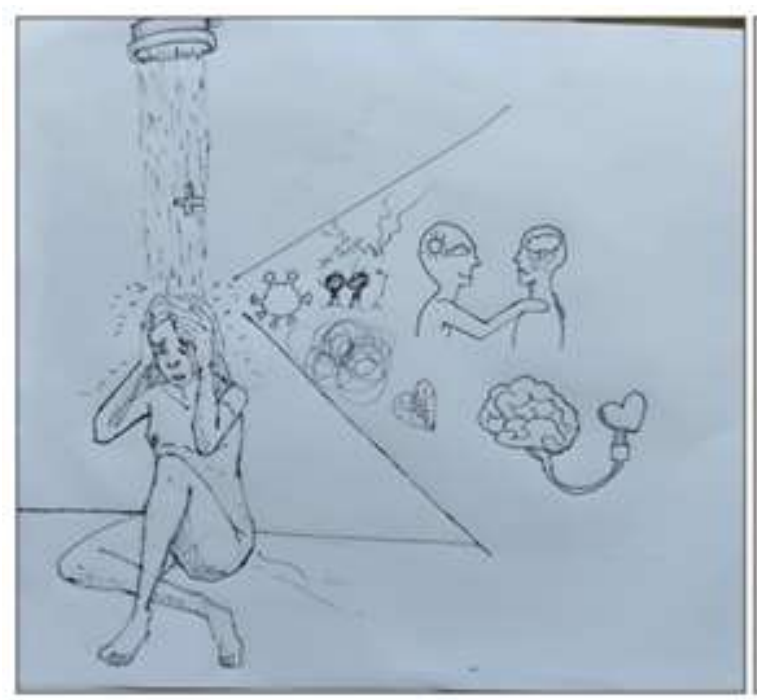

A

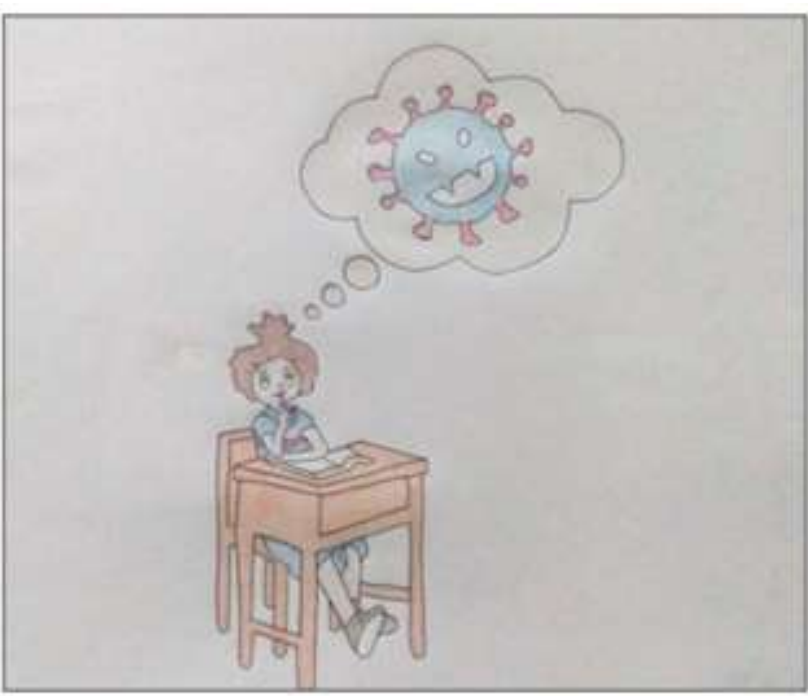

B

Fonte: Arquivo pessoal dos autores.

Conforme aparece na primeira nuvem de palavras, reafirmado no desenho da Figura 7A, o sentimento de medo é um mecanismo de defesa animal para adaptação social. Esta emoção atrelada a tristeza pode aumentar os níveis de ansiedade, como apresentado na primeira nuvem de palavras, podendo intensificar transtornos psiquiátricos pré-existentes em alguns indivíduos (Shigemura et al., 2020)

O último eixo temático de categorização dos desenhos foi o impacto macro e microssocial, representado por dois desenhos na Figura 8. Para esse grupo de alunos, no contexto micro, a pandemia impacta de modo regional as cidades, bairros, ruas e casas, enquanto no pensamento macro, todo o planeta é afetado.

Figura 8. Principais desenhos que agrupam o eixo temático, impacto macro e microssocial.

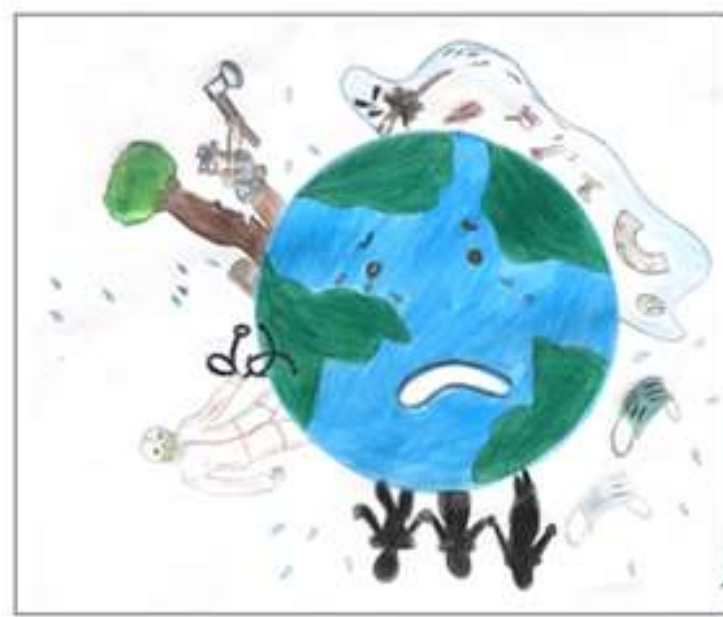

A

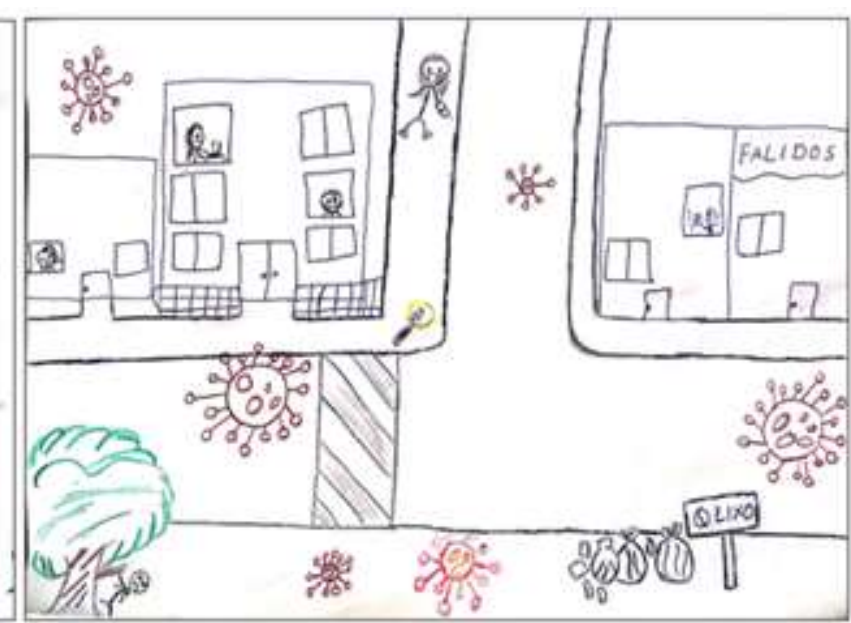

B

Fonte: Arquivo pessoal dos autores.

O planeta Terra triste com sua população ilhada em grandes grupos sociais, uns com privilégios adquiridos e outros sem o mínimo de garantias sociais para viver, foi a representação de um dos alunos (Figura 8A), que trouxe alguns elementos unidos à nossa rotina, como as máscaras de proteção individual. No desenho seguinte, o aluno representou a região de uma 
cidade, com os comércios fechados (representados pela placa "falidos") e a população recolhida em suas residências, ao passo que os vírus seguem livres nas ruas e avenidas circulando e disseminando a doença (Figura 8B).

Estes desenhos estimularam os alunos na integração dos conhecimentos e das relações que coexistem entre ciência, tecnologia, sociedade e meio ambiente. Além disso, são estudantes universitários de licenciatura plena, em processo de habilitação para a docência na educação básica, logo a aprendizagem por investigação é um fator chave na formação técnica, humana e crítica destes alunos, propiciando uma educação libertadora.

\section{Considerações Finais}

A formação de professores é um processo dinâmico que deve dialogar com as tendências sociais e com o ambiente do sujeito em formação. A pandemia da Covid-19 segue impactando o modo de vida das sociedades com reflexos em todas as áreas e dimensões da vida humana. Deste modo, pensar no processo de ensino e aprendizagem, tomando como base as inquietações e necessidades dos alunos é de grande relevância. No curso de Ciências Biológicas, a vocação para a educação ambiental é um imperativo na formação profissional, devendo ser realizada de modo holístico e transversal.

O uso de sequências didáticas são recursos, que para além de diversificar as aulas, permitem a promoção da aprendizagem significativa e problematizadora dos estudantes, futuros profissionais da educação. Este tema é muito caro para os professores de biologia, que por muitas vezes precisam articular junto à comunidade estratégias de educação ambiental pautadas no desenvolvimento sustentável, mesmo com os entraves da pandemia. Não obstante, grandes desafios estão para além da esfera de ação dos professores, como a implementação de políticas públicas voltadas para mitigar os impactos ambientais, em detrimento dos efeitos diretos e indiretos da pandemia da Covid-19.

Vale salientar que esta sequência didática é um processo dinâmico que agrupou um conjunto de atividades estruturadas e articuladas com objetivos específicos de aprendizagem, sendo planejada e replanejada simultaneamente a sua implementação. Logo, esta proposta de dialogar com as relações existentes entre a pandemia da Covid-19 e os impactos ao meio ambiente, pode ser adaptada para a realidade do ensino médio, técnico e tecnológico, abrangendo outras temáticas sensíveis para o ensino, o fazer pedagógico e a formação humana.

\section{Agradecimentos}

Os autores agradecem aos sujeitos da pesquisa, que se disponibilizaram em participar do estudo, bem como ao docente da disciplina de Princípios de Etnobiologia e Educação Ambiental. Ao apoio institucional da Faculdade De Educação, Ciências e Letras de Iguatu, unidade da Universidade Estadual do Ceará.

\section{Referências}

Acosta, A. (2019). O bem viver: uma oportunidade para imaginar outros mundos. Editora Elefante.

Arrais, R., Carvalho, A., \& Teo, I. (2016). Entre a esquerda e a direita: uma reflexão política. Edições Textos Para Reflexão, 2016.

Boff, L. (2020). "Pós - Covid-19: que visão de mundo e que valores desenvolver?” Portal Eletrônico Leonardo Boff [08/05/2020]. https://leonardoboff.org/2020/05/08pos-covid-19-que-visão-de-mundo-desenvolver/.

Braga, F., Scarpa, G. M., Brando, V. E., Manfè, G., \& Zaggia, L. (2020). COVID-19 lockdown measures reveal human impact on water transparency in the Venice Lagoon. Science of The Total Environment, 736, 139612.

Brooks, S. K., Webster, R. K., Smith, L. E., Woodland, L., Wessely, S., Greenberg, N., \& Rubin, G. J. (2020). The psychological impact of quarantine and how to reduce it: rapid review of the evidence. The Lancet, 395(10227), 912-920.

Castellar, S. M. V., \& Machado, J. C. (2016) Metodologias ativas: Sequências Didáticas. FTD.

Enumo, S. R. F., Linhares, \& M. B. M. (2020). Contribuições da Psicologia no contexto da Pandemia da COVID-19: seção temática. Estudos de Psicologia (Campinas), 37. 
Freire, P. (2000). Pedagogia da Indignação: Cartas pedagógicas e outros escritos. (3a ed.), Editora UNESP.

Gadotti, M. (2011). Boniteza de um sonho: ensinar-e-aprender com sentido. (3a ed.), Editora e Livraria Instituto Paulo Freire.

Gutiérrez, F., \& Prado, C. (2013). Ecopedagogia e cidadania planetária. (3a ed.), Cortez.

Holmes, E. A., O'Connor, R. C., Perry, V. H., Tracey, I., Wessely, S., Arseneault, L., Ballard, C., Christensen, H., Silver, R. C., Everall, I., Ford, T., John, A., Kabir, T., King, K., Madan, I., Michie, S., Przybylski, A. K., Shafran, R., Sweeney, A., Worthman, C. M., Yardley, L., Cowan, K., Cope, C., Hotopf, M., \& Bullmore, E. (2020). Multidisciplinary research priorities for the COVID-19 pandemic: a call for action for mental health science. The Lancet Psychiatry.

Huang, C., Wang, Y., Li, X., Ren, L., Zhao, J., Hu, Y., ... Zhang, L., Fan, G., Xu, J., Gu, X., Cheng, Z., Yu, T., Xia, J., Wei, Y., Wu, W., Xie, X., Yin, W., Li, H., Liu, M., Xiao, Y., Gao, H., Guo, L., Xie, J., Wang, G., Jiang, R., Gao, Z., Jin, Q., Wang, J., \& Cao, B. (2020). Clinical features of patients infected with 2019 novel coronavirus in Wuhan, China. The lancet, 395(10223), 497-506.

Lefèvre, F., \& Lefèvre, A. M. C. (2000). Os novos instrumentos no contexto da pesquisa qualitativa. Caxias do Sul: EDUCS. In: Lefèvre, F., Lefèvre, A. M. C., \& Teixeira, J. J. V. (Orgs.). O discurso do sujeito coletivo: uma nova abordagem metodológica em pesquisa qualitativa. EDUCS, 11-35.

Maia, B. R., \& Dias, P. C. (2020). Ansiedade, depressão e estresse em estudantes universitários: o impacto da COVID-19. Estudos de Psicologia (Campinas), 37.

Marques, R. (2020). Responsabilidade social: senso crítico versus covid-19. Boletim de Conjuntura (BOCA), 2(4), 90-94.

Méheut, M. (2005). Teaching-learning sequences tools for learning and/or research. In: Boersma, K., Goedhart, M., Jong, O. D., \& Eijkelhof, H. (Orgs.). Research and the quality of science education. Springer, 195-207.

Minayo, M. C. S., Assis, S. G., \& Souza, E. R. (Eds.). (2005). Avaliação por triangulação de métodos: abordagem de programas sociais. SciELO-Editora FIOCRUZ.

Moreira, H., \& Caleffe, L. G. (2008). Metodologia da pesquisa para o professor pesquisador. (2a ed.), Lamparina.

Moreira, M.A. (2015). Teorias de aprendizagem. EPU.

Neves, M. C. P., \& Marques, V. S. (2017). Ética aplicada: ambiente. Edições 70.

Nogueira, D. N. G., Aligleri, L., \& Sampaio, C. P. (2020). Resíduos de Serviços de Saúde: implicações no cenário da pandemia do novo coronavírus. Advances in Nursing and Health, 2, 11-15.

Nouaillas, O. (2020). Bruno Latour, Nicolas Hulot, François Ruffin: comment le covid-19 peut relancer la mutation écologique. http://www.lavie.fr/actualite/ecologie/bruno-latour-nicolas-hulot-francois-ruffin-comment-le-covid-19-peut-relancer-la-mutation-ecologique-14-04-2020105490_8.php.

Ozili, P. K., \& Arun, T. (2020). Spillover of COVID-19: impact on the Global Economy. SSRN Preprints, 3562570.

Peng, J., Wu, X., Wang, R., Li, C., Zhang, Q., \& Wei, D. (2020). Medical waste management practice during the 2019-2020 novel coronavirus pandemic: Experience in a general hospital. American Journal of Infection Control, 48(8), 918-921.

Pereira, A. C., Silva, G. Z., \& Carbonari, M. E. E. (2011). Sustentabilidade, responsabilidade social e meio ambiente. Saraiva.

Portal G1, (2020a). Covid-19: estudo analisa impacto do 'momento único de silêncio' nos oceanos provocado pela pandemia. https:/g1.globo.com/natureza/noticia/2021/04/12/covid-19-estudo-analisa-impacto-do-momento-unico-de-silencio-nos-oceanos-provocado-pelapandemia.ghtml.

Portal G1, (2020b). Por que economia em marcha lenta não freou mudança climática na pandemia? https://g1.globo.com/natureza/noticia/2021/04/11/porque-economia-em-marcha-lenta-nao-freou-mudanca-climatica-na-pandemia.ghtml.

Puig, M. B. J-A. (2010). Argumentación y evaluación de explicaciones causales en ciencias: el caso de la inteligencia. Alambique Didáctica de las Ciencias Experimentales, 63, 11-18.

Rashid, T., Seligman, \& M. P. (2018). Positive psychotherapy: clinical manual. Oxford University Press.

Reigota, M. (2017). O que é Educação Ambiental. (2a ed.), Brasiliense.

Sachs, I. (2008). Desenvolvimento: includente, sustentável e sustentado. Gramond.

Sauvé, L. (2016). Viver juntos em nossa Terra: Desafios contemporâneos da educação ambiental. Revista Contrapontos, 16(2), $288-299$.

Saviani, D. (2020). Crise estrutural, conjuntura nacional, coronavírus e educação-o desmonte da educação nacional. Revista Exitus, 10 , e020063-e020063.

Shigemura, J., Ursano, R. J., Morganstein, J. C., Kurosawa, M., \& Benedek, D. M. (2020). Public responses to the novel 2019 coronavirus (2019-nCoV) in Japan: Mental health consequences and target populations. Psychiatry and clinical neurosciences, 74(4), 281.

Silva, J. O. (2020). Incidência de doenças causadas pelo impacto ambiental em um lixão no município de Bacabal-MA. TCC (Graduação) - Curso de Ciências Biológicas, Universidade Federal do Maranhão, Bacabal.

Tucci, V., Moukaddam, N., Meadows, J., Shah, S., Galwankar, S. C., \& Kapur, G. B. (2017). The forgotten plague: psychiatric manifestations of Ebola, Zika, and emerging infectious diseases. Journal of Global Infectious Diseases, 9(4), 151. 
Research, Society and Development, v. 10, n. 5, e57410515671, 2021

(CC BY 4.0) | ISSN 2525-3409 | DOI: http://dx.doi.org/10.33448/rsd-v10i5.15671

Wang, C., Pan, R., Wan, X., Tan, Y., Xu, L., Ho, C. S., \& Ho, R. C. (2020). Immediate psychological responses and associated factors during the initial stage of the 2019 coronavirus disease (COVID-19) epidemic among the general population in China. International Journal of Environmental Research and Public Health, 17(5), 1729.

WHO, World Health Organization (2020). Coronavirus disease 2019 (COVID-19) Situation Report Genebra: WHO. 